\title{
Use of methylene blue in vasoplegic syndrome that developed during non-cardiac surgery - A case report -
}

Received October 10, 2018

Revised 1st, October 31, 2018

2nd, December 3, 2018

3rd, January 31, 2019

Accepted February 1, 2019

\section{Corresponding author}

Jeong-Hyun Choi, M.D., Ph.D.

Department of Anesthesiology and

Pain Medicine, Kyung Hee University

Hospital, 23 Kyungheedae-ro,

Dongdaemun-gu, Seoul 02447,

Korea

Tel: 82-2-958-8589

Fax: 82-2-958-8580

E-mail: choikhang@gmail.com

ORCID

https://orcid.org/0000-0003-1995-1220

\section{In Duk Oh, Eunsil Shin, Jong-Mi Jeon, Hyunho Woo, and Jeong-Hyun Choi}

Department of Anesthesiology and Pain Medicine, Kyung Hee University College of Medicine, Seoul, Korea

\begin{abstract}
Background: Vasoplegic syndrome is an increasingly recognized disease in perioperative medicine and is characterized by severe hypotension, normal or elevated cardiac output, and decreased systemic vascular resistance. It occurs commonly after cardiopulmonary bypass but may also occur after other types of surgery.
\end{abstract}

Case: Vasoplegic syndrome developed in our patient during posterior lumbar interbody fusion because of administering nicardipine after phenylephrine. However, the blood pressure did not increase as expected despite simultaneous use of norepinephrine and vasopressin to increase the reduced systemic vascular resistance.

Conclusions: We present a case of vasoplegic syndrome that developed during posterior lumbar interbody fusion and was treated successfully with methylene blue.

Keywords: Methylene blue; Nicardipine; Vasoplegia.
Vasoplegic syndrome is increasingly recognized in perioperative medicine and is characterized by severe hypotension, normal or elevated cardiac output, and decreased systemic vascular resistance (SVR) [1]. This syndrome is associated with preoperative use of angiotensin-converting enzyme inhibitors, intravenous heparin, cardiopulmonary bypass, transplant surgery, trauma, and sepsis [2-4]. A large amount of fluid, catecholaminergic vasoconstrictors, vasopressin, and methylene blue can be used as treatment [3,5]. Vasoplegic syndrome is common after cardiopulmonary bypass but sometimes occurs after other types of surgery $[1,3,5]$. We present a case of vasoplegic syndrome that developed during posterior lumbar interbody fusion and was treated successfully with methylene blue.

\section{CASE REPORT}

A 77-year-old woman (height $148.5 \mathrm{~cm}$, weight $70 \mathrm{~kg}$ ) was admitted to undergo posterior lumbar interbody fusion for lumbar spinal stenosis (L1-3). She had hypertension that was treated with amlodipine (a calcium channel blocker) and carvedilol (a beta-blocker). The preoperative leukocyte count was $7,770 / \mathrm{ml}$ with a hemoglobin level of $14.1 \mathrm{mg} / \mathrm{dl}$, hematocrit $40.1 \%$, and a platelet count of $268,000 / \mathrm{ml}$. Chest radiography, electrocardiogram (ECG), and physical examination were normal. A central venous catheter was inserted into the right subclavian vein on the day before surgery to monitor central venous pressure and for infusion of fluids and blood.

The patient arrived in the operating room without premedication. ECG, non-invasive blood pressure (BP), and pulse oximetry monitors were applied. Before induction of anesthesia, BP was 130/90 $\mathrm{mmHg}$, heart rate (HR) was 75 beats/

This is an Open Access article distributed under the terms of the Creative Commons Attribution Non-Commercial License (http://creativecommons.org/licenses/by-nc/4.0) which permits unrestricted non-commercial use, distribution, and reproduction in any medium, provided the original work is properly cited. 
min in sinus rhythm, and peripheral oxygen saturation was $100 \%$. Anesthesia was induced by adjusting the target propofol $(3.0 \mu \mathrm{g} / \mathrm{dl})$ and remifentanil (3.5-6.0 ng/dl) concentrations according to the Schnider and Minto model with a target concentration infusion pump (Orchestra, Fresenius Kabi, Germany). Rocuronium $50 \mathrm{mg}$ was administered after confirming loss of consciousness. Endotracheal intubation was performed after cessation of spontaneous breathing. Immediately after intubation, the patient's BP was $130 / 70 \mathrm{mmHg}$ and $\mathrm{HR}$ was 80 beats/min. A right radial artery cannula was inserted for continuous monitoring of arterial pressure, and central venous pressure was continuously monitored through the central venous line. Cardiac output, stroke volume variation (SVV), and SVR were monitored continuously using the FloTrac/EV1000 device (Edwards Lifesciences, USA). After arterial cannulation, the cardiac index (CI) was $2.8 \mathrm{~L} / \mathrm{min} / \mathrm{m}^{2}$, SVR index (SVRI) was 2,394 dynes.sec $/ \mathrm{cm}^{5} / \mathrm{m}^{2}$, mean arterial BP was $95 \mathrm{mmHg}$, HR was 77 beats/min, SVV was $12 \%$, and central venous pressure was $13 \mathrm{mmHg}$. Preoperative arterial blood gas analysis recorded a $\mathrm{pH}$ of $7.455, \mathrm{pCO}_{2}$ of 32.9 $\mathrm{mmHg}, \mathrm{pO}_{2}$ of $203.7 \mathrm{mmHg}$, and hematocrit ratio of $34 \%$.

Forty-five minutes after the start of surgery, the patient's mean arterial BP decreased to $56 \mathrm{mmHg}$ and her SVRI decreased to 1,932 dynes.sec $/ \mathrm{cm}^{5} / \mathrm{m}^{2}$. Therefore, $50 \mu \mathrm{g}$ of phenylephrine was administered. About 2 min later, her mean arterial BP increased rapidly to $123 \mathrm{mmHg}$ and her SVRI increased sharply to 4,254 dynes $\cdot \mathrm{sec} / \mathrm{cm}^{5} / \mathrm{m}^{2}$. To control the rapid increase in $\mathrm{BP}, 500 \mu \mathrm{g}$ nicardipine $\mathrm{HCl}$ (Perdipine injection $^{\circledR}$, Dong-A Pharm., Korea) was administered. Thereafter, her mean arterial BP decreased rapidly to $47-59 \mathrm{mmHg}$. The SVV was $15 \%$ and the cardiac index was in the normal range at $2.7-3.3 \mathrm{~L} / \mathrm{min} / \mathrm{m}^{2}$, but the SVRI remained low at 1,079 1,242 dynes.sec $/ \mathrm{cm}^{5} / \mathrm{m}^{2}$. To recover the mean arterial BP and SVRI, a bolus of phenylephrine was repeated, but this time the mean arterial BP did not increase above $60 \mathrm{mmHg}$. Four units of packed red blood cells were transfused for recovery of the intraoperative blood loss. After completion of the transfusion, the hemoglobin level was $11.0 \mathrm{mg} / \mathrm{dl}$, hematocrit was $31.5 \%$, and the platelet count was $144,000 / \mathrm{ml}$. The mean arterial BP remained at $47-58 \mathrm{mmHg}$, SVRI at 1,097-1,550 dynes.sec $/ \mathrm{cm}^{5} / \mathrm{m}^{2}$, and cardiac index at $2.2-2.8 \mathrm{~L} / \mathrm{min} / \mathrm{m}^{2}$ despite fluid replacement and repeated phenylephrine administration. Norepinephrine was administered at a rate of $0.1 \mu \mathrm{g} / \mathrm{kg} / \mathrm{min}$ and then increased to $0.3 \mu \mathrm{g} / \mathrm{kg} / \mathrm{min}$, but the mean arterial BP remained at $60 \mathrm{mmHg}$ and SVRI at 1,239 dynes.sec $/ \mathrm{cm}^{5} / \mathrm{m}^{2}$. No skin rash or urticaria was observed when the patient's skin was checked for an anaphylactic reaction, and there was no change in peak airway pressure. After the end of surgery, sugammadex $140 \mathrm{mg}$ was administered to restore spontaneous respiration and reverse muscle relaxation. Spontaneous breathing resumed, the patient recovered consciousness, and the endotracheal tube was removed. The patient was then transferred to the post-anesthesia care unit (PACU) while receiving intravenous norepinephrine $0.1 \mu \mathrm{g} /$ $\mathrm{kg} / \mathrm{min}$. Fig. 1 shows the changes in vital signs during surgery.

On arrival in the PACU, the patient was conscious with a BP of $82 / 64 \mathrm{mmHg}$, an $\mathrm{HR}$ of 78 beats/min, and a peripheral oxygen saturation of $100 \%$. Although MBP remained above $60 \mathrm{mmHg}$, we suspected that the patient had vasoplegia because of the lower than expected blood pressure, despite proper fluid replacement and blood transfusion. Therefore, vasopressin was initiated at $2 \mathrm{U} / \mathrm{h}$ because norepinephrine alone had not recovered the BP. Immediately after vasopressin administration, her BP increased to 104/64 mmHg but decreased to $82 / 57 \mathrm{mmHg} 20 \mathrm{~min}$ later. Findings on a 12-lead ECG in the PACU were normal. Transthoracic echocardiogra-

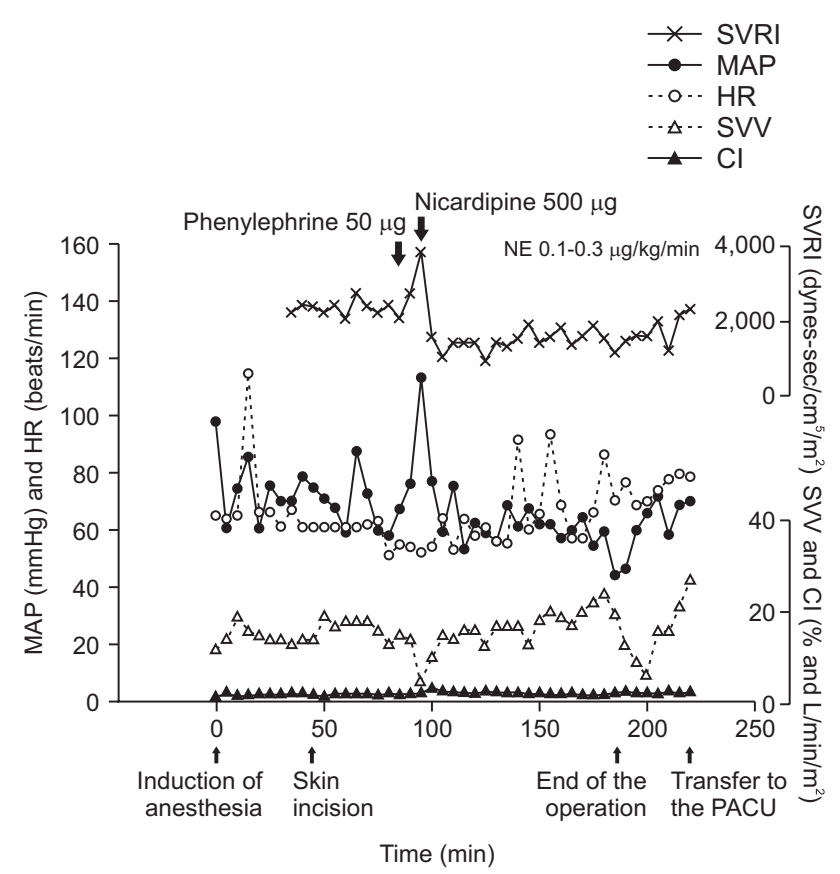

Fig. 1. Mean arterial pressure and heart rate during anesthesia in the operating room. Cl: cardiac index, HR: heart rate, MAP: mean arterial pressure, NE: norepinephrine, SVRI: systemic vascular resistance index, SW: stroke volume variation, PACU: post-anesthesia care unit. 


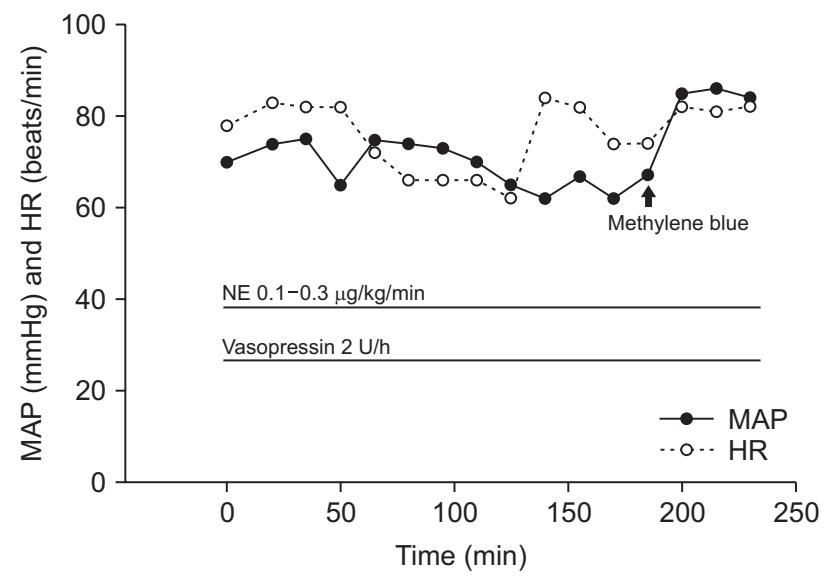

Fig. 2. Mean arterial pressure (MAP) and heart rate (HR) during the immediate postoperative period in the post-anesthesia care unit. NE: norepinephrine.

phy was performed to rule out cardiogenic shock and showed normal ventricular volume and left ventricular systolic function (left ventricular ejection fraction 65\%), no regional wall motion abnormality, and no pericardial effusion or hematoma. We excluded cardiogenic, anaphylactic, and hypovolemic causes of hypotension, and assumed that the patient had developed vasoplegic syndrome. Given the lack of response to a vasopressor, we administered methylene blue at a dose of $0.5 \mathrm{mg} / \mathrm{kg}$ ( $35 \mathrm{mg}$ ), which is less than the usual dose, over 20 min. There was an immediate increase in BP from 74/54 $\mathrm{mmHg}$ to 112/66 mmHg. However, about $15 \mathrm{~min}$ later, the patient vomited, so the methylene blue was discontinued immediately. The total dose of methylene blue was $26 \mathrm{mg}$. The systolic BP remained above $110 \mathrm{mmHg}$; therefore, the patient was transferred to the intensive care unit where she received a sustained infusion of norepinephrine $0.2 \mu \mathrm{g} / \mathrm{kg} / \mathrm{min}$ and vasopressin $2 \mathrm{U} / \mathrm{h}$. Fig. 2 shows the change in vital signs in the PACU. On the first postoperative day, the systolic BP was maintained above $110 \mathrm{mmHg}$ and $\mathrm{HR}$ at about 80 beats/min. The norepinephrine and vasopressin were then tapered and stopped. The patient was transferred to a general ward on the second postoperative day and was discharged on postoperative day 16 without any complications.

\section{DISCUSSION}

Vasoplegic syndrome is defined as a cardiac output of $>$ $2.5 \mathrm{~L} / \mathrm{min} / \mathrm{m}^{2}$ and an SVRI of $<1,600$ dynes. $\mathrm{sec} / \mathrm{cm}^{5} / \mathrm{m}^{2}$ with severe hypotension despite administration of a large amount of fluid to increase the intravascular volume and a vasoconstrictor [6]. We performed several evaluations to identify the cause of the patient's hypotension. There were no abnormal findings on the ECG after surgery. Furthermore, there was no decrease in cardiac output and there were no cardiac abnormalities on transthoracic echocardiography. The hemodynamic changes, including hypotension, could have been misdiagnosed as anaphylaxis, hypovolemia, or cardiogenic shock in this patient. However, she received an adequate amount of fluid and a blood transfusion, and echocardiographic and skin findings were normal. Therefore, these conditions were excluded and vasoplegic syndrome was diagnosed. Vasoplegia has been reported most frequently after cardiac surgery with cardiopulmonary bypass and has also been reported in non-cardiac major surgery, such as liver transplantation. However, there has been no report of a sudden onset due to intraoperative drug use like that seen in our patient.

Normally, vascular smooth muscle contraction is induced by the rise of the cytosolic $\mathrm{Ca}^{2+}$ concentration. Therefore, the vascular tone is determined by the influx and removal of $\mathrm{Ca}^{2+}$. Vasoplegia may occur if multiple intrinsic and extrinsic regulation failures occur. The causes of vasoplegia can be classified as pathogen-associated, damage-associated, and other mechanisms [7]. Sepsis is predominantly a response to the pathogen-associated mechanism. Damage-associated vasoplegia includes burns or polytrauma. Anaphylaxis, neurogenic, and drug-associated mechanisms may cause vasoplegia. Nitric oxide (NO) is a critical intrinsic regulator of vascular tone and the endothelial-derived relaxing factor causing vasodilation. It is known that nitric oxide plays a role in the development of vasoplegic syndrome. It is generated from calcium-dependent isoforms of NO synthase. Our patient developed vasoplegia due to drug-associated mechanisms. Administering nicardipine immediately after phenylephrine injection may have caused vasoplegic syndrome. From a general point of view, the mechanism of action of dihydropyridine (DHP)-type calcium antagonists is based on the inhibition of the smooth muscle L-type calcium current, thus decreasing the intracellular calcium concentration and inducing smooth muscular relaxation. However, it has been shown that DHPs can induce the release of NO from the vascular endothelium and platelets [8]. Amlodipine resulted in significantly increased NO formation in the porcine coronary vessels and long-term preincubation ( $24 \mathrm{~h}$ ) with amlodipine 
induced a significant increase in the NO bioavailability in porcine aortic endothelial cell cultures [9]. This NO-releasing effect was a group phenomenon shared by the DHPs [8]. When we used nicardipine to counteract the effects of phenylephrine during surgery, our patients developed vasoplegic syndrome. Although the exact pathophysiology of vasoplegic syndrome cannot be determined in this patient, the use of nicardipine during surgery is thought to trigger NO-releasing, which may be related to the occurrence of vasoplegic syndrome. In addition, our patient was taking amlodipine for preoperative hypertension. It is worth investigating whether these drugs are more vulnerable to this phenomenon.

The primary treatment for vasoplegic syndrome is a catecholamine vasoconstrictor, including dopamine, epinephrine, norepinephrine, or phenylephrine, to stimulate the $\alpha \mathrm{l}$ adrenergic receptor and increase mean arterial pressure. Norepinephrine is a very potent vasoconstrictor and has the following advantages compared with other BP-raising agents. First, the vasoconstrictive effect is similar to that of epinephrine or phenylephrine and is greater than that of dopamine. Second, unlike epinephrine, norepinephrine does not act on the $\beta 2$ adrenergic receptor, so lactate levels do not increase. Third, unlike dopamine and epinephrine, norepinephrine does not increase HR. Therefore, cardiac output can be increased without excessively increasing the myocardial oxygen demand. Fourth, whereas phenylephrine acts only on the $\alpha 1$ adrenergic receptor, norepinephrine also acts on the $\beta 1$ adrenergic receptor, thereby maintaining ventricular-arterial coupling. Therefore, norepinephrine increases the mean arterial pressure without causing much of an increase in HR, so can be used as a primary treatment for vasoplegic syndrome. However, catecholamine resistance is frequently present in vasoplegic syndrome, and high-dose catecholamine therapy has various side effects. Although vasopressin alone does not seem to reduce the mortality risk, it is known to increase mean arterial pressure at a low dose as effectively as norepinephrine and to reduce the need for concomitant use of norepinephrine [10]. However, BP did not increase in our patient as expected despite the simultaneous use of norepinephrine and vasopressin to increase the reduced SVR.

Vasoplegic syndrome that does not respond to potent vasoconstrictors is difficult to treat. Methylene blue may effectively treat severe vasoplegic syndrome [3,5]. Methylene blue binds to guanylate cyclase competitively with nitric ox- ide, which plays an important role in vasodilatation, thereby reducing production of cGMP and inhibiting vasodilatation. Methylene blue is administered as a bolus dose of 1-2 mg/ kg over 10-20 min [5]. Several case reports and observational studies revealed that methylene blue administration early after surgery can improve mean arterial pressure, decrease the requirement for a vasoconstrictor, reduce the mortality risk, and decrease the duration of vasoplegic syndrome [11-13]. Therefore, methylene blue can be used to treat vasoplegic syndrome that does not respond to catecholamine vasoconstrictors.

Methylene blue has a number of adverse effects, including arrhythmia, coronary artery spasm, angina pectoris, decreased cardiac output, decreased renal and mesenteric blood flow, and increased pulmonary arterial pressure. Prolonged peripheral intravenous administration may cause localized skin necrosis and interfere with oxygen saturation monitoring, thereby causing relatively low oxygen saturation. Other side effects include confusion, headache, fever, nausea, vomiting, abdominal pain, and sweating [5]. Doses higher than $7 \mathrm{mg} / \mathrm{kg}$ may cause hemolysis, methemoglobinemia, chest pain, and hypertension, while doses higher than 20 $\mathrm{mg} / \mathrm{kg}$ can lead to severe intravascular hemolysis, hyperbilirubinemia, and death. Methylene blue is contraindicated in patients taking monoamine oxidase inhibitors because it can cause serotonin syndrome [14]. Methylene blue should not be administered to pregnant women because it can increase expression of nitric oxide in the placenta, leading to fetal hypoxia. In patients with glucose-6-phosphate dehydrogenase deficiency, methylene blue administration may cause hemolytic anemia $[5,15]$.

In conclusion, our patient developed vasoplegic syndrome when administered nicardipine to offset the effects of phenylephrine during posterior lumbar interbody fusion. The vasoplegic syndrome responded poorly to norepinephrine and vasopressin treatment but did respond to methylene blue. Therefore, it should be considered that the cause of vasoplegic syndrome in our case may be nicardipine, which is a calcium channel blocker used during surgery.

\section{CONFLICTS OF INTEREST}

No potential conflict of interest relevant to this article was reported. 


\section{ORCID}

In Duk Oh: https://orcid.org/0000-0001-5372-0843

Eunsil Shin: https://orcid.org/0000-0003-0939-3704

Jong-Mi Jeon: https://orcid.org/0000-0002-5169-8563

Hyunho Woo: https://orcid.org/0000-0002-6970-2399

\section{REFERENCES}

1. Gomes WJ, Carvalho AC, Palma JH, Gonçalves I Jr, Buffolo E. Vasoplegic syndrome: a new dilemma. J Thorac Cardiovasc Surg 1994; 107: 942-3.

2. Mekontso-Dessap A, Houël R, Soustelle C, Kirsch M, Thébert D, Loisance DY. Risk factors for post-cardiopulmonary bypass vasoplegia in patients with preserved left ventricular function. Ann Thorac Surg 2001; 71: 1428-32.

3. Levy B, Fritz C, Tahon E, Jacquot A, Auchet T, Kimmoun A. Vasoplegia treatments: the past, the present, and the future. Crit Care 2018; 22: 52.

4. Omar S, Zedan A, Nugent K. Cardiac vasoplegia syndrome: pathophysiology, risk factors and treatment. Am J Med Sci 2015; 349: 80-8.

5. McCartney SL, Duce L, Ghadimi K. Intraoperative vasoplegia: methylene blue to the rescue! Curr Opin Anaesthesiol 2018; 31: 43-9.

6. Liu H, Yu L, Yang L, Green MS. Vasoplegic syndrome: an update on perioperative considerations. J Clin Anesth 2017; 40: 63-71.

7. Lambden S, Creagh-Brown BC, Hunt J, Summers C, Forni LG. Definitions and pathophysiology of vasoplegic shock. Crit Care
2018; $22: 174$.

8. Dhein S, Salameh A, Berkels R, Klaus W. Dual mode of action of dihydropyridine calcium antagonists: a role for nitric oxide. Drugs 1999; 58: 397-404.

9. Berkels R, Taubert D, Bartels H, Breitenbach T, Klaus W, Roesen R. Amlodipine increases endothelial nitric oxide by dual mechanisms. Pharmacology 2004; 70: 39-45.

10. Russell JA, Walley KR, Singer J, Gordon AC, Hébert PC, Cooper DJ, et al. Vasopressin versus norepinephrine infusion in patients with septic shock. N Engl J Med 2008; 358: 877-87.

11. Levin RL, Degrange MA, Bruno GF, Del Mazo CD, Taborda DJ, Griotti JJ, et al. Methylene blue reduces mortality and morbidity in vasoplegic patients after cardiac surgery. Ann Thorac Surg 2004; 77: 496-9.

12. Maslow AD, Stearns G, Butala P, Schwartz CS, Gough J, Singh AK. The hemodynamic effects of methylene blue when administered at the onset of cardiopulmonary bypass. Anesth Analg 2006; 103: 2-8.

13. Ozal E, Kuralay E, Yildirim V, Kilic S, Bolcal C, Kücükarslan N, et al. Preoperative methylene blue administration in patients at high risk for vasoplegic syndrome during cardiac surgery. Ann Thorac Surg 2005; 79: 1615-9.

14. Fischer GW, Levin MA. Vasoplegia during cardiac surgery: current concepts and management. Semin Thorac Cardiovasc Surg 2010; $22:$ 140-4.

15. Faber P, Ronald A, Millar BW. Methylthioninium chloride: pharmacology and clinical applications with special emphasis on nitric oxide mediated vasodilatory shock during cardiopulmonary bypass. Anaesthesia 2005; 60: 575-87. 